\title{
Informing Cyber Threat Intelligence through Dark Web Situational Awareness: The AZSecure Hacker Assets Portal
}

\author{
SAGAR SAMTANI, Department of Operations and Decision Technologies, Indiana University \\ WEIFENG LI, Department of Management Information Systems, University of Georgia \\ VICTOR BENJAMIN, Department of Information Systems, Arizona State University \\ HSINCHUN CHEN, Department of Management Information Systems, University of Arizona
}

\begin{abstract}
To increase situational awareness, major cybersecurity platforms offer Cyber Threat Intelligence (CTI) about emerging cyber threats, key threat actors, and their modus operandi. However, this intelligence is often reactive, as it analyzes event log files after attacks have already occurred, lacking more active scrutiny of potential threats brewing in cyberspace before an attack has occurred. One intelligence source receiving significant attention is the Dark Web, where significant quantities of malicious hacking tools and other cyber assets are hosted. We present the AZSecure Hacker Assets Portal (HAP). The Dark Web-based HAP collects, analyzes, and reports on the major Dark Web data sources to offer unique perspective of hackers, their cybercriminal assets, and their intentions and motivations, ultimately contributing CTI insights to improve situational awareness. HAP currently supports 200+ users internationally from academic institutions such as UT San Antonio and National Taiwan University, law enforcement entities such as Calgary and Ontario Provincial Police, and industry organizations including General Electric and PayPal.
\end{abstract}

CCS Concepts: • Security and privacy $\rightarrow$ Malware and its mitigation; • Information systems $\rightarrow$ Data analytics;

Additional Key Words and Phrases: Situational awareness, dark web, cyber threat intelligence, systems development

ACM Reference format:

Sagar Samtani, Weifeng Li, Victor Benjamin, and Hsinchun Chen. 2021. Informing Cyber Threat Intelligence through Dark Web Situational Awareness: The AZSecure Hacker Assets Portal. Digit. Threat.: Res. Pract. 2, 4, Article 27 (October 2021 ), 9 pages.

https://doi.org/10.1145/3450972

This material is based upon work supported by the National Science Foundation under Grant Numbers OAC-1917117 (CICI), CNS-1936370 (SaTC CORE), CNS-1850362 (CRII SaTC), and DGE-2038483 (SaTC-EDU).

Authors' addresses: S. Samtani, Department of Operations and Decision Technologies, Indiana University, 1275 E. 10th St., Bloomington, Indiana 47405, USA; email: ssamtani@iu.edu; W. Li, Department of Management Information Systems, University of Georgia, 630 S. Lumpkin St., Athens, GA 30602, USA; email: weifeng.li@uga.edu; V. Benjamin, Department of Information Systems, Arizona State University, 300 E. Lemon St., Tempe, AZ 85287, USA; email: victor.benjamin@asu.edu; H. Chen, Department of Management Information Systems, University of Arizona, 1130 E. Helen St., McClelland Hall 430, Tucson, AZ 85721, USA; email: hsinchun.chen@arizona.edu.

Permission to make digital or hard copies of all or part of this work for personal or classroom use is granted without fee provided that copies are not made or distributed for profit or commercial advantage and that copies bear this notice and the full citation on the first page. Copyrights for components of this work owned by others than ACM must be honored. Abstracting with credit is permitted. To copy otherwise, or republish, to post on servers or to redistribute to lists, requires prior specific permission and/or a fee. Request permissions from permissions@acm.org.

(c) 2021 Association for Computing Machinery.

2576-5337/2021/10-ART27 \$15.00

https://doi.org/10.1145/3450972

Digital Threats: Research and Practice, Vol. 2, No. 4, Article 27. Publication date: October 2021. 


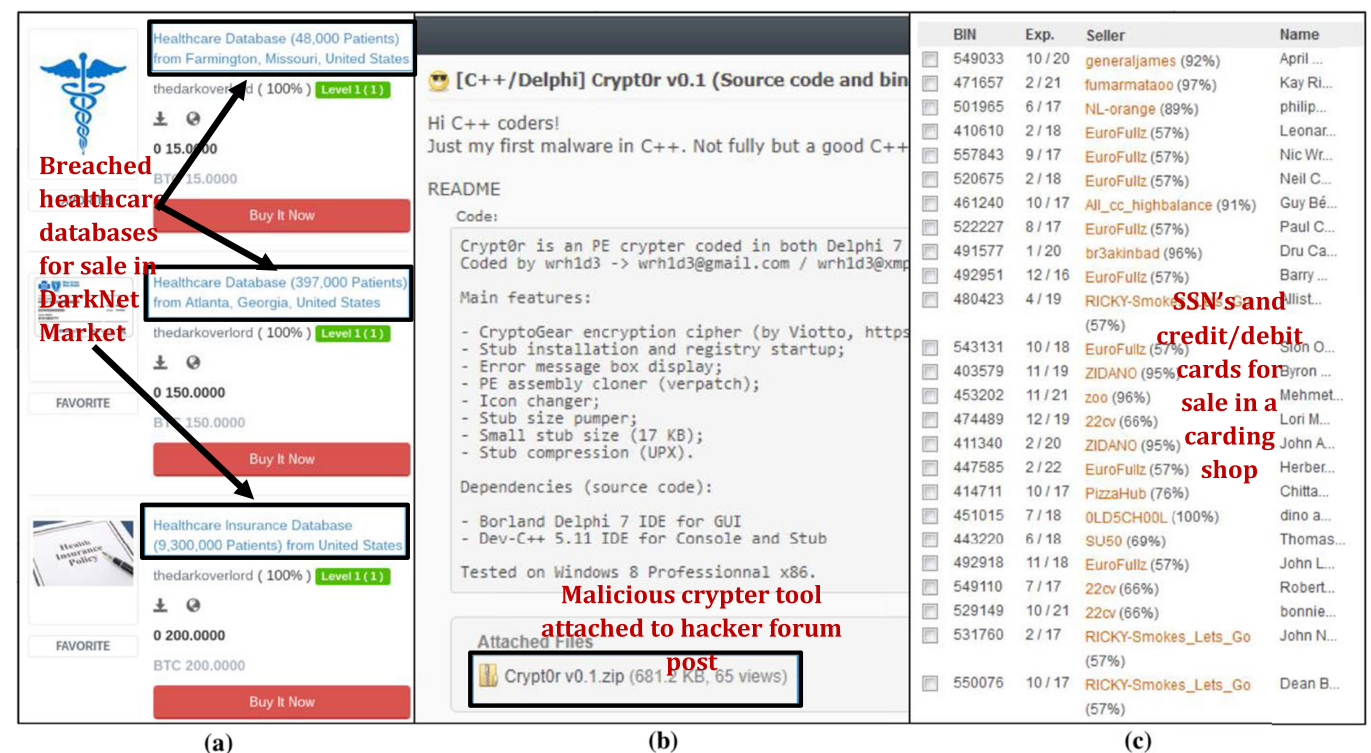

Fig. 1. (a) Healthcare databases for sale on DNM; (b) crypter source code, a key technology for ransomware shared on forums; (c) credit/debit cards and SSNs for sale in a carding shop.

\section{INTRODUCTION}

Cybersecurity researchers and practitioners have developed numerous security controls to help organizations improve their cybersecurity posture. To help organizations increase situational awareness [10], major industry cybersecurity platforms such as Shadowserver and QRadar offer Cyber Threat Intelligence (CTI) about emerging cyber threats and key threat actors [4]. These platforms typically curate intelligence for dissemination to stakeholders via visualizations and/or regular reports. However, this intelligence often lacks the situational awareness of potential threats from cyberspace, as it consists of post-mortem analysis of attacks after they have already occurred [7]. Recognizing this issue, the SANS Institute has urged CTI platforms to leverage "external threat intelligence sources to help alert the organization of threats it was not previously aware of" [4]. One such data source receiving significant attention is the Dark Web. The Dark Web includes hundreds of online markets and social media platforms where millions of hackers globally trade and sell significant quantities malicious hacking tools, content, knowledge, and other cyber assets on hacker forums, DarkNet Marketplaces (DNMs), Internet-Relay-Chat (IRC), and carding shops [3]. The Dark Web also contains information and marketplaces for illicit goods, such as drugs; the system described in this manuscript focuses explicitly on cybersecurity topics. Figure 1 illustrates sample Dark Web content.

The Dark Web's breadth of malicious cybercriminal knowledge and tools has enabled hackers to execute large-scale cyber-attacks. An example includes the Mirai botnet leaked on forums that infected millions of Internet of Things devices that denied service to major Internet DNS servers [10]. Such cases underscore the Dark Web's viability for developing awareness of cybercriminal activities and novel CTI [1]. However, anti-crawling measures, multi-lingual content, unstructured data, unfamiliar hacker knowledge, and massive data volume has slowed critically needed CTI research on the Dark Web.

This article presents a novel Dark Web-based CTI system, the AZSecure Hacker Assets Portal (HAP). Developed by the AI Lab at the University of Arizona and funded by NSF's Scholarship-for-Service (SFS) and Secure and Trustworthy Cyberspace programs, HAP's design was guided by feedback from CTI sharing organizations such as Policing in Cyberspace (POLCYB) and National Cyber Forensics Training Alliance (NCFTA) 
Table 1. Overview and CTI Value of Dark Web Data Sources

\begin{tabular}{|c|c|c|c|c|}
\hline Platform & Data Sources & Description & $\begin{array}{l}\text { Example } \\
\text { Platforms }\end{array}$ & CTI Value \\
\hline \multirow[t]{3}{*}{$\begin{array}{l}\text { Hacker } \\
\text { Forums }\end{array}$} & Leaked forums & $\begin{array}{l}\text { Forums that have been } \\
\text { leaked to the general public }\end{array}$ & $\begin{array}{l}\text { Antichat, } \\
\text { Blackhackerz, } \\
\text { Blackhat World }\end{array}$ & \multirow{3}{*}{$\begin{array}{l}\text {-Discussions mentioning past and } \\
\text { future attacks } \\
\text {-Advertisements for hacking } \\
\text { services (e.g., DDoS for hire) } \\
\text {-Free hacking tutorials and } \\
\text { exploits (e.g., SQLi, BlackPOS) } \\
\text {-Identify key threat actors } \\
\text {-Discover emerging } \\
\text { hacking/threats }\end{array}$} \\
\hline & Seized forums & $\begin{array}{l}\text { Forums that have been shut } \\
\text { down and seized by law } \\
\text { enforcement }\end{array}$ & $\begin{array}{l}\text { Darkode, } \\
\text { shadowcrew, } \\
\text { cardersmarket }\end{array}$ & \\
\hline & Active forums & $\begin{array}{l}\text { Active, accessible forums } \\
\text { that have not been seized } \\
\text { or are offline }\end{array}$ & $\begin{array}{l}\text { OpenSC, } \\
\text { Ashiyane, } \\
\text { reverse4you, } \\
\text { exelab }\end{array}$ & \\
\hline $\begin{array}{l}\text { Carding/Fullz } \\
\text { Shops }\end{array}$ & $\begin{array}{l}\text { Carding/Fullz } \\
\text { shops }\end{array}$ & $\begin{array}{l}\text { Shops selling stolen } \\
\text { credit/debit cards and } \\
\text { sensitive information (e.g., } \\
\text { Social Security Numbers, } \\
\text { drivers licenses, insurance } \\
\text { cards) }\end{array}$ & $\begin{array}{l}\text { cardershop, } \\
\text { BESTVALID, } \\
\text { rescatorccfullz, } \\
\text { fullzshop }\end{array}$ & $\begin{array}{l}\text {-Identify breached individuals and } \\
\text { organizations } \\
\text {-Discover trends of afflicted } \\
\text { financial service industries }\end{array}$ \\
\hline $\begin{array}{l}\text { Internet- } \\
\text { Relay-Chat }\end{array}$ & $\begin{array}{l}\text { Active IRC } \\
\text { Channels }\end{array}$ & $\begin{array}{l}\text { Clear-text, instant } \\
\text { messaging, communication } \\
\text { that is not stored }\end{array}$ & $\begin{array}{l}\text { Anonops, } \\
\text { whyweprotest, } \\
\text { anonet, } \\
\text { opddosisis }\end{array}$ & $\begin{array}{l}\text {-Preferred method of } \\
\text { communication for hacktivist } \\
\text { groups (e.g., Anonymous) } \\
\text {-Since chats are not logged, } \\
\text { hackers more freely share hacking } \\
\text { knowledge and targets }\end{array}$ \\
\hline \multirow[t]{2}{*}{$\begin{array}{l}\text { DarkNet } \\
\text { Markets }\end{array}$} & Grams & $\begin{array}{l}\text { Search engine for } \\
\text { identifying DNMs }\end{array}$ & & $\begin{array}{l}\text {-Identify markets to collect to } \\
\text { generate CTI }\end{array}$ \\
\hline & $\begin{array}{l}\text { Active market } \\
\text { website }\end{array}$ & $\begin{array}{l}\text { Active marketplaces that } \\
\text { have not been seized }\end{array}$ & $\begin{array}{l}\text { Minerva, } \\
\text { therealdeal, } \\
\text { dream market }\end{array}$ & $\begin{array}{l}\text {-Identify new, emerging exploits } \\
\text { (0-days, ransomware) } \\
\text {-Discover breached content (e.g., } \\
\text { logins) } \\
\text {-Early indicator for breached } \\
\text { companies } \\
\text {-Identify key sellers/buyers }\end{array}$ \\
\hline
\end{tabular}

to provide real-time CTI data, capabilities, and situational awareness to cybersecurity researchers and educators, government agencies, and industry professionals. It contains data similar to what can be found in Figure 1, including datapoints featured in published academic studies [3]. Specifically, HAP:

- Collects a comprehensive set of Dark Web platforms.

- Synergistically incorporates state-of-the-art CTI, data mining, and text mining methodologies to organize Dark Web contents into the HAP interface to facilitate content browsing, searching, and downloading.

- Offers dynamic visualizations for scholars to systematically gain situational awareness through exploring the vast Dark Web and formulate novel scholarly research inquiries related to emerging threat detection, key hacker identification, data fusion, and others.

\section{DARK WEB CONTENT AND DARK WEB-BASED CTI PLATFORMS}

Each Dark Web platform offers distinct CTI value. We provide a summary data sources, descriptions, example platforms, and CTI value for each platform in Table 1. 
Table 2. Selected Industry and Academic Dark Web-based CTI Platforms

\begin{tabular}{|c|c|c|c|c|c|c|c|}
\hline \multirow[t]{2}{*}{ Sector } & \multirow[t]{2}{*}{ Platform } & \multicolumn{4}{|c|}{ Dark Web Data Source } & \multirow[t]{2}{*}{ Analytics* } & \multirow[t]{2}{*}{ Operational Intel $^{*}$} \\
\hline & & Forum & DNM & C. Shop & IRC & & \\
\hline \multirow[t]{12}{*}{ Industry } & Verint & $\sqrt{ }$ & $\sqrt{ }$ & NL & $\mathrm{NL}$ & Network/text & Portal, API \\
\hline & Skybox Security & $\sqrt{ }$ & $\sqrt{ }$ & NL & NL & NL & Portal, Feeds \\
\hline & LookingGlass & $\sqrt{-}$ & NL & NL & Yes & ML & Portal, API \\
\hline & Recorded Future & $\sqrt{ }$ & $\sqrt{ }$ & $\sqrt{ }$ & NL & ML, NLP & Portal, Feeds \\
\hline & Blueliv & NL & $\sqrt{ }$ & NL & NL & $\mathrm{NL}$ & Portal \\
\hline & Digital Shadows & $\sqrt{ }$ & $\sqrt{ }$ & $\mathrm{NL}$ & $\mathrm{NL}$ & Basic search & Portal, API \\
\hline & Flashpoint & $\sqrt{ }$ & NL & $\sqrt{ }$ & NL & Search, SME & API \\
\hline & Surfwatch Labs & $\sqrt{-}$ & $\sqrt{ }$ & No & No & SME, search & Portal \\
\hline & ZeroFox & NL & $\sqrt{ }$ & No & No & Search & Portal, API \\
\hline & CYR3CON & $\sqrt{ }$ & $\sqrt{ }$ & $\mathrm{NL}$ & $\mathrm{NL}$ & Rule-based & Blogs, feeds \\
\hline & DarkOwl & $\sqrt{ }$ & $\sqrt{ }$ & $\sqrt{ }$ & $\sqrt{ }$ & $\mathrm{NL}$ & Portal, feeds \\
\hline & Experian & NL & $\sqrt{ }$ & $\sqrt{ }$ & $\mathrm{NL}$ & Search & Portal \\
\hline \multirow[t]{6}{*}{ Academic } & AZSecure DIBBs & $\sqrt{-}$ & $\sqrt{ }$ & $\sqrt{ }$ & $\sqrt{ }$ & None & Newsletters \\
\hline & $\begin{array}{l}\text { Intl. CyberCrime } \\
\text { Research }\end{array}$ & $\sqrt{ }$ & $\sqrt{ }$ & No & No & NL & Newsletters \\
\hline & IARPA CAUSE & $\sqrt{ }$ & $\sqrt{ }$ & $\sqrt{ }$ & $\sqrt{ }$ & ML & Newsletters \\
\hline & $\begin{array}{l}\text { Cambridge Cybercrime } \\
\text { Centre }\end{array}$ & $\sqrt{ }$ & No & No & No & None & Newsletters \\
\hline & IMPACT & No & $\sqrt{ }$ & No & No & NL & Papers/data \\
\hline & MEMEX & $\sqrt{ }$ & $\sqrt{ }$ & $\mathrm{NL}$ & $\sqrt{ }$ & $\mathrm{NL}$ & Papers/data \\
\hline
\end{tabular}

* Note: $\mathrm{NL}=$ Not Listed; ML=Machine Learning; API=Application Programming Interface; SME=Subject Matter Expert; NLP=Natural Language Processing.

Hackers use forums and/or IRC to discuss TTPs, share exploits, and advertise services or products to other hackers [3]. Hackers can contact promoters or navigate to DNMs or shops to purchase goods. Live platforms contain anti-crawling measures that block web crawlers. The overhead required to comprehensively collect active platforms often limits collection to small subsets of Dark Web data or only one platform Dark Web platform type [3]. However, numerous industry and academic hacker community-based CTI platforms have emerged. Table 2 summarizes platforms based on their data, analytics, and operational intel as listed on each organization's websites.

Most entities only gather selected platforms. This prevents a holistic view of hacker activities. Further, the volume, multi-lingual, and jargon-laden nature of Dark Web text require novel procedures tuned to these unique characteristics to maximize CTI precision. Some systems are not CTI focused (e.g., MEMEX), do not provide analytics (e.g., DIBBs), or lack scalable operational intelligence capabilities (e.g., CAUSE). These limitations motivate a novel CTI system with (1) a comprehensive set of hacker community platforms and (2) carefully designed analytics for system organization and situational awareness research opportunities.

\section{AZSECURE HACKER ASSETS PORTAL SYSTEM OVERVIEW}

HAP (Figure 2) collects, analyzes, and reports on the four major Dark Web data sources to offer unique perspective of hackers, their cybercriminal assets, and their intentions and motivations, ultimately contributing deep, relevant, and new CTI insights and research opportunities for academia, industry, and governments.

Digital Threats: Research and Practice, Vol. 2, No. 4, Article 27. Publication date: October 2021. 


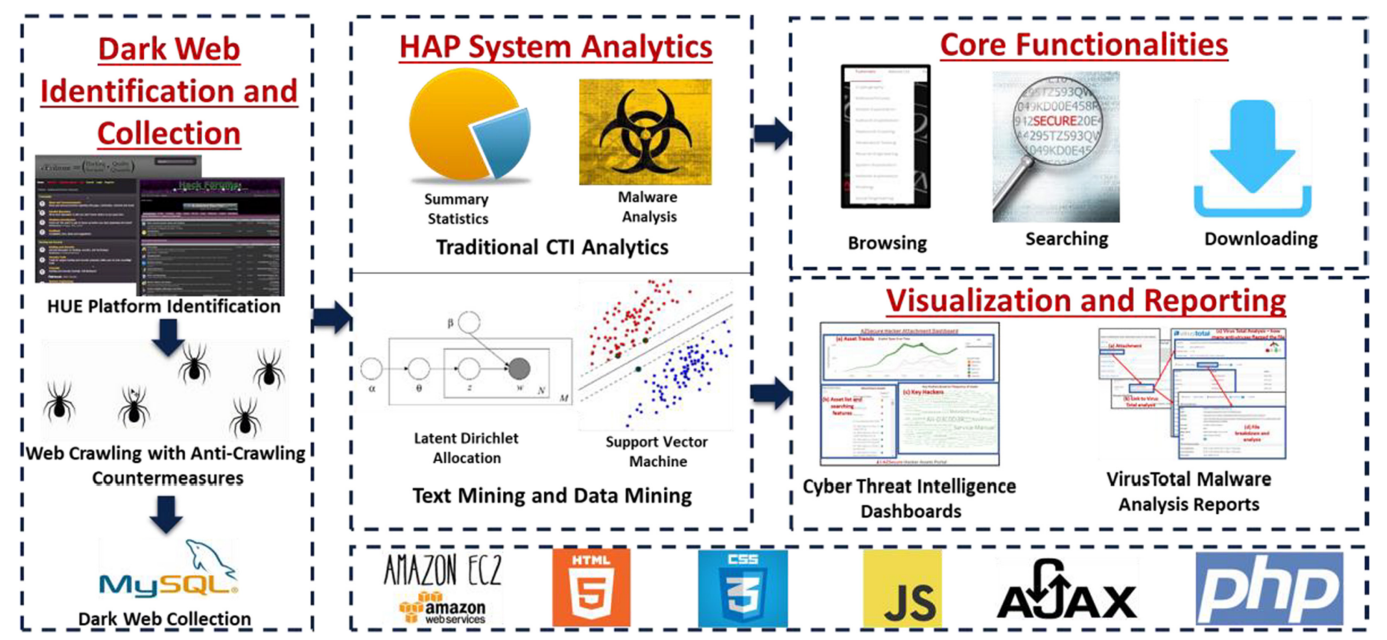

Fig. 2. AZSecure HAP System Design.

Table 3. AZSecure Dark Web Data Collection Strategies

\begin{tabular}{|l|l|l|}
\hline $\begin{array}{l}\text { Anti-crawling } \\
\text { Mechanism }\end{array}$ & \multicolumn{1}{|c|}{ Description } & \multicolumn{1}{c|}{ Countermeasure } \\
\hline AJAX & $\begin{array}{l}\text { Webpage content is transmitted } \\
\text { through AJAX so that HTML does } \\
\text { not contain sensitive information }\end{array}$ & $\begin{array}{l}\text { Discover and exploit the link requesting data in } \\
\text { the AJAX code }\end{array}$ \\
\hline CAPTCHA & $\begin{array}{l}\text { Decide whether the request came } \\
\text { from a human or bot }\end{array}$ & $\begin{array}{l}\text { Solve CAPTCHA manually, then load the } \\
\text { generated session cookie afterwards }\end{array}$ \\
\hline DDoS Prevention & $\begin{array}{l}\text { Server detects IP request patterns } \\
\text { block suspicious IPs }\end{array}$ & $\begin{array}{l}\text { 1. Fine-tune crawling rates and request with } \\
\text { random patterns to emulate human behavior } \\
\text { 2. Constantly alter source IP addresses }\end{array}$ \\
\hline IP Range Block & Blacklists IP ranges to block requests & Reroute requests through private proxy servers \\
\hline Session Timer & Automatic user log outs & Edit expiration date of the website cookie \\
\hline User-agent Check & $\begin{array}{l}\text { The server verifies requests come } \\
\text { from a legit browser, rather than a } \\
\text { crawler }\end{array}$ & $\begin{array}{l}\text { Wrap requests with headers containing } \\
\text { user-agent information }\end{array}$ \\
\hline User Authentication & Requires login with credentials & $\begin{array}{l}\text { 1. Log into platform manually for the first time } \\
\text { and load generated session cookie afterwards } \\
\text { 2. Fill out the login form automatically }\end{array}$ \\
\hline
\end{tabular}

\subsection{Dark Web Identification and Collection}

We collected active platforms based on SFS, POLCYB, and NCFTA feedback for maximum CTI value. We developed novel counter anti-crawling measures (Table 3) to bypass all current known Dark Web collection barriers. It is possible that in the future, new anti-crawling measures can be developed and employed by Dark Web communities that would require further efforts to be circumvented. This is typical of the arms race between cybersecurity professionals and cybercriminals. Overall, these collection strategies enable automated and comprehensive data collection.

Custom parsers augmented with each anti-crawling mechanism countermeasure extracted CTI-relevant attributes such as screennames, post/listing content, and timestamps. These procedures yielded 10,975,390 records 
Table 4. Summary of AZSecure HAP Data Collection

\begin{tabular}{|l|l|l|l|l|}
\hline Platform & $\begin{array}{c}\text { Number } \\
\text { Collected }\end{array}$ & $\begin{array}{l}\text { Number of } \\
\text { Records }\end{array}$ & \multicolumn{1}{|c|}{ Languages } & \multicolumn{1}{|c|}{ Contents } \\
\hline Hacker Forums & 34 forums & $3,643,216$ & $\begin{array}{l}\text { English, Russian, } \\
\text { Arabic, Chinese }\end{array}$ & $\begin{array}{l}\text { Advertisements of credentials (bank } \\
\text { accounts, PayPal, health), } \\
\text { ransomware, mobile malware, } \\
\text { phishing, botnets, tutorials }\end{array}$ \\
\hline $\begin{array}{l}\text { DarkNet } \\
\text { Marketplaces }\end{array}$ & 9 markets & 80,075 & English, Russian, Dutch & $\begin{array}{l}\text { Listings of credentials (bank } \\
\text { accounts, PayPal, health), exploits } \\
\text { (SQLi, 0-days), tutorials, malware }\end{array}$ \\
\hline Carding/Fullz Shops & 26 Shops & $6,471,839$ & English & SSNs, debit/credit cards \\
\hline IRC Channels & 21 Channels & 767,630 & English & $\begin{array}{l}\text { Hacktivism, DDoS, and general } \\
\text { hacking discussions }\end{array}$ \\
\hline Total: & 90 Platforms & $\sim 10,975,390$ & $\begin{array}{l}\text { English, Russian, } \\
\text { Arabic, Dutch, Chinese }\end{array}$ & - \\
\hline
\end{tabular}

spanning 2002-2020. Table 4 summarizes the number of platforms collected, the number of extracted data records, language coverage, and available contents.

\subsection{HAP System Analytics}

HAP synergistically combines CTI analysis, text mining, and data mining to organize and present Dark Web data for users to search, sort, browse, and download assets. Major exploit categories highlighted by the platform were identified using topic extraction on hacker platform content. VirusTotal, a popular Google-based static malware analyzer reports each malware's operations (e.g., worm, keylogger, Trojan, etc.). Figure 3 illustrates how a retailer can search for point-of-sale (POS) malware. POS malware gained popularity after Target's breach. By searching for "POS," they can pinpoint BlackPOS (the malware used against Target), identify when, where, and who posted it, and learn malware implementation details.

\subsection{Core Functionalities and Visualization and Reporting}

HAP also provides a set of interactive CTI dashboards by aggregating (e.g., post date, hacker screenname, asset category, etc.). This allows users to discover asset trends, pinpoint key hackers, and identify assets. Figure 4 illustrates how a user can filter on a time point for system-based exploits to identify key hackers and assets posted at that time. Users can further filter on hacker names to identify a hacker's assets and posting trends. Besides the hacker forum exploit dashboards, the HAP also includes dashboards for DarkNet Marketplaces.

\section{AZSECURE HAP'S PRACTICAL CYBERSECURITY IMPLICATIONS FOR SITUATIONAL AWARENESS}

The scale, breadth, and depth of HAP data enables numerous novel CTI analytics. Table 5 summarizes five promising CTI opportunity areas provided by HAP. Each inquiry's possible approaches are carefully selected based on each platform's characteristics, past literature, and the method's strengths as it pertains to their respective research direction.

Given the broad nature of the discipline, CTI is often segmented into strategic, operational, and tactical levels of focus. Each level has specified job roles and responsibilities as it pertains to the overall CTI lifecycle. Each component of the HAP holds value to selected stakeholders from both research and practice perspectives. Table 6 provides a brief summary of the different intelligence levels, example stakeholders, the relevant HAP component(s) that can offer value to those stakeholders, and selected security implications. The following sub-sections provide a further discussion of each level. 


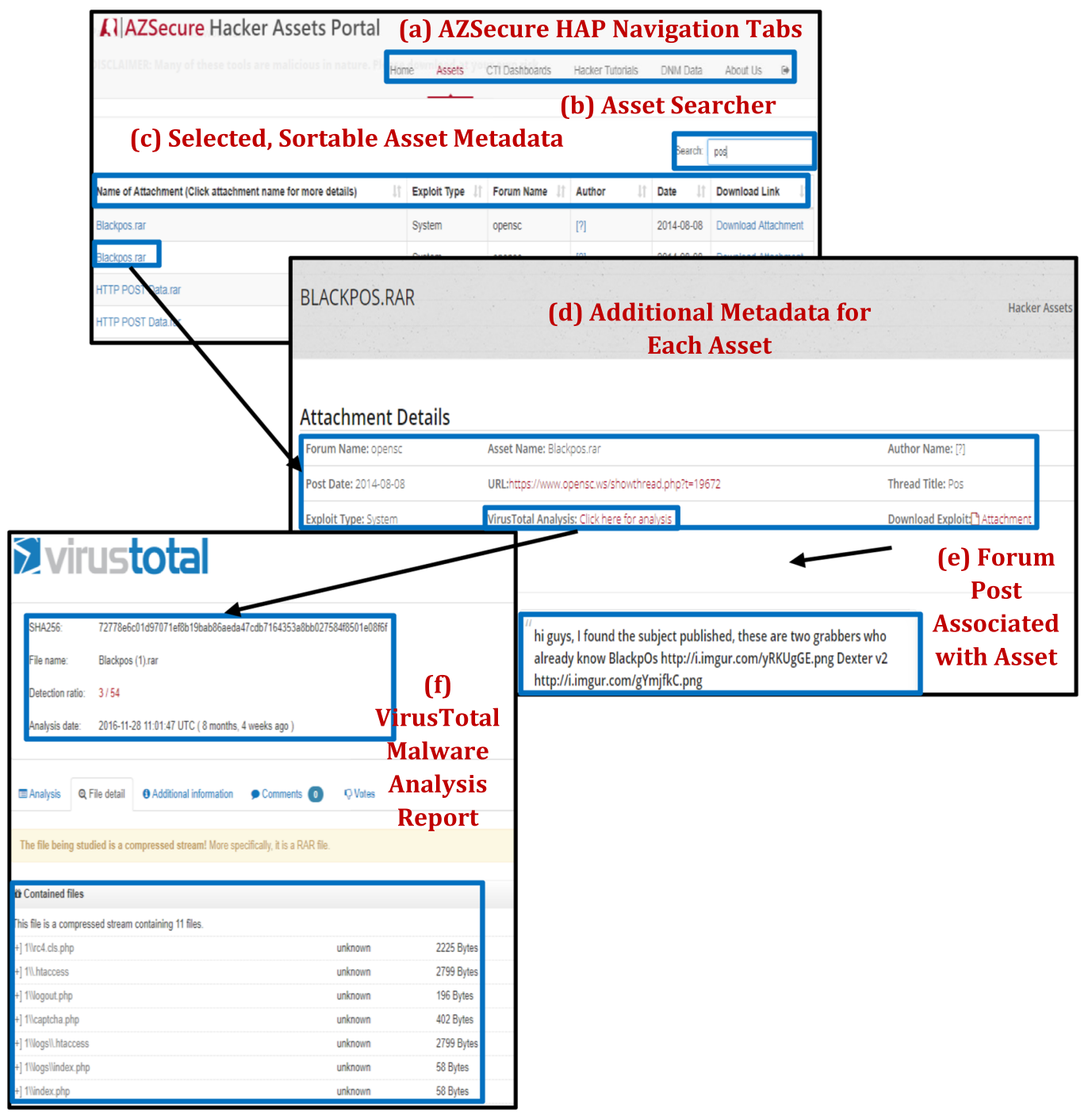

Fig. 3. HAP provides (a) a navigation for browsing. Users can (b) search and (c) sort assets based on name, type, author, and others. They can also download assets directly. Clicking on an asset provides (d) additional metadata and (e) the Dark Web posting that accompanied the asset. Users can also get a full VirusTotal malware summary (f). Full technical details and additional analysis are available at [3].

\subsection{Strategic Intelligence}

Strategic CTI focuses on allocating resources towards the cybersecurity concerns facing an organization. Chief Information Security Officer's and other management must effectively communicate the security needs of their organization using reports that feature critical information and visualizations to executive management and other stakeholders regarding attainment of investments in cybersecurity defense. The visualizations can also play an important role in presenting striking visualizations to guide security investments. 

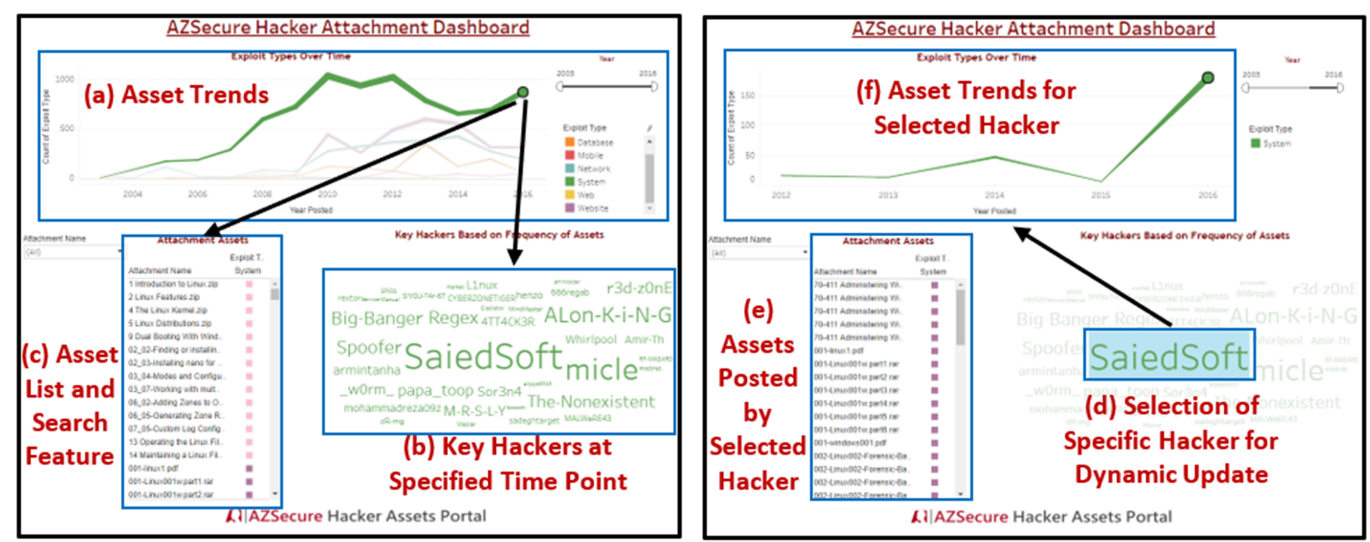

Fig. 4. The CTI Dashboards in the HAP allow users to (a) identify trends of specific asset types, (b) key hackers, and (c) assets at specific time points. Users can further (d) select hackers of interest and identify (e) assets and (f) asset trends.

Table 5. Summary of Selected CTI Research Inquiries Possible with HAP Data

\begin{tabular}{|c|c|c|c|}
\hline CTI Area & CTI Research Inquiry & Dataset(s) & Possible Approach(es) \\
\hline \multirow[t]{3}{*}{ Threat Detection } & Detecting emerging exploits & Forums, IRC, DNMs & Bayesian Forecasting \\
\hline & Source code evolution & Forums & Syntax trees \\
\hline & Hacker language evolution & Forums, IRC, DNMs & Diachronic linguistics \\
\hline \multirow{3}{*}{$\begin{array}{l}\text { Key Hacker } \\
\text { Identification }\end{array}$} & Identifying key hackers & Forums, IRC & Network analysis \\
\hline & Key seller identification & DNMs, Carding shops & Econometrics \\
\hline & Hacker longevity/persistence & IRC, Forums & Survival analysis \\
\hline \multirow[t]{2}{*}{$\begin{array}{l}\text { Multi-lingual } \\
\text { analysis }\end{array}$} & DNM sentiment analysis & Forums, DNMs & $\begin{array}{l}\text { Deep Transfer Learning, } \\
\text { Adversarial Learning }\end{array}$ \\
\hline & Machine translation & Forums, DNMs, IRC & \\
\hline \multirow{2}{*}{$\begin{array}{l}\text { Global hacker } \\
\text { surveillance }\end{array}$} & Cross-platform data fusion & Forums, IRC, DNMs & Multi-source analysis \\
\hline & Fusion with log files & $\begin{array}{l}\text { Forum exploit data, } \\
\text { network logs }\end{array}$ & $\begin{array}{l}\text { Deep Structured Semantic } \\
\text { Models }\end{array}$ \\
\hline \multirow{2}{*}{$\begin{array}{l}\text { Cybersecurity } \\
\text { visualization }\end{array}$} & Code evolution & Source code in forums & Network/tree visualizations \\
\hline & Spatial carding crime analysis & Shops & Geo-spatial dashboards \\
\hline
\end{tabular}

Table 6. Summary of Selected Security Implications for AZSecure HAP for Varying Levels of Cyber Threat Intelligence

\begin{tabular}{|l|l|l|l|}
\hline Intelligence Level & \multicolumn{1}{|c|}{$\begin{array}{c}\text { Selected } \\
\text { Stakeholders }\end{array}$} & $\begin{array}{c}\text { Relevant HAP } \\
\text { Component(s) }\end{array}$ & \multicolumn{1}{|c|}{ Security Implications } \\
\hline Strategic & Security managers & Dashboards & Guiding security investments \\
\cline { 3 - 4 } & Visualization & Threat reporting \\
\hline Operational & IR Team & Reporting & $\begin{array}{l}\text { Threat discovery \& } \\
\text { assessment, }\end{array}$ \\
\cline { 3 - 4 } & Summary statistics & $\begin{array}{l}\text { Monitoring, escalating, \& } \\
\text { detecting IOC }\end{array}$ \\
\hline Tactical & Malware Analysts & $\begin{array}{l}\text { Malware analysis, } \\
\text { summary statistics }\end{array}$ & \\
\hline
\end{tabular}




\subsection{Operational Intelligence}

Operational CTI is focused on threat discovery, assessment, remediation, and reporting incidents to strategic and tactical levels of CTI. A key issue curtailing effective situational awareness is information overload. HAP's visualization, reporting and summary statistics can offer intuitive approach to bypassing large tables of data. Summary statistics provide analysts the ability to dynamically create a representation of threats without any prior knowledge and help prioritize top threats and facilitate subsequent remediation activities. Further helping facilitate summary statistics, this visualization can offer significant value in categorizing and clustering threats and target platforms.

\subsection{Tactical Intelligence}

Tactical intelligence focuses on monitoring, escalating, and detecting Indicators of Compromises (IoCs), executing remediation exercises (e.g., patching vulnerable systems). These indicators are subsequently fed into selected security systems and reporting formats by SOC analysts, malware analysts, and individuals in similar roles. Common challenges that these job functions face include threat identification and prioritization. HAP's malware analysis and summary statistics can offer value to help address these issues. Both provide valuable tactical leads for CTI professionals. An example for the generated intelligence would be the integration of new rules into Security Information and Event Management (SIEM) systems. Using the intelligence provided by the malware analysis and summary statistics, the SIEM can quarantine or alert tactical intelligence security analysis if the IoCs appear within devices on their network.

\section{CONCLUSIONS AND FUTURE DIRECTIONS}

Interested readers can contact the lead author for access to the portal. Given the sensitive nature of Dark Web data, registrants will be asked to identify themselves and summarize their intended HAP use. HAP currently supports 200+ users internationally from academic institutions such as UT San Antonio and National Taiwan University, law enforcement entities such as Calgary and Ontario Provincial Police, and industry including General Electric and PayPal. Advanced HAP functions will be developed to help organizations identify relevant Dark Web data for their vulnerabilities and enable efficient Dark Web data dissemination. Both additions will help HAP serve as a model for the next generation of CTI platforms.

\section{REFERENCES}

[1] Sadia Afroz, Vaibhav Garg, Damon McCoy, and Rachel Greenstadt. 2013. Honor among thieves: A common's analysis of cybercrime economies. In Proceedings of the eCrime Researchers Summit. 1-11.

[2] Mohammed Almukaynizi, Eric Nunes, Krishna Dharaiya, Manoj Senguttuvan, Jana Shakarian, and Paulo Shakarian. 2017. Proactive identification of exploits in the wild through vulnerability mentions online. In Proceedings of the 2017 International Conference on Cyber Conflict (CyCon U.S.'17), 82-88.

[3] Victor Benjamin, Joseph S. Valacich, and Hsinchun Chen. 2019. DICE-E: A framework for conducting darknet identification, collection, evaluation, with ethics. MIS Quart. 43, 1 (2019), 1-22.

[4] Matt Bromiley. 2016. Threat Intelligence: What it is, and how to use it effectively. Retrieved June 5, 2017 from https://www.sans.org/ reading-room/whitepapers/analyst/threat-intelligence-is-effectively-37282.

[5] David Décary-Hétu and Dominique Laferrière. 2015. Discrediting vendors in online criminal markets. In Disrupting Criminal Networks: Network Analysis in Crime Prevention. 1-27.

[6] Ernst \& Young Global Limited. 2014. Cyber threat intelligence-How to get ahead of cybercrime. Retrieved from http://www.ey.com/ Publication/vwLUAssets/EY-cyber-threat-intelligence-how-to-get-ahead-of-cybercrime/\$FILE/EY-cyber-threat-intelligence-howto-get-ahead-of-cybercrime.pdf.

[7] Sanjay Goel. 2011. Cyberwarfare. Commun. ACM 54, 8 (Aug. 2011), 132.

[8] Luke Graham. 2017. Cybercrime costs the global economy $\$ 450$ billion: CEO. Retrieved June 5, 2017 from https://www.cnbc.com/2017/ 02/07/cybercrime-costs-the-global-economy-450-billion-ceo.html.

[9] Tracy Kitten. 2014. Target Malware: Exploring the Origins. Retrieved June 5, 2017 from http://www.bankinfosecurity.com/interviews/ intelcrawler-i-2161.

Digital Threats: Research and Practice, Vol. 2, No. 4, Article 27. Publication date: October 2021. 
[10] Jan Kohlrausch and Eugene A. Brin. 2020. ARIMA supplemented security metrics for quality assurance and situational awareness. Digit. Threats: Res. Pract. 1, 1, Article 6 (Mar. 2020), 1-21. DOI : https://doi-org.proxy-remote.galib.uga.edu/10.1145/3376926

Received April 2020; revised April 2021; accepted February 2021

Digital Threats: Research and Practice, Vol. 2, No. 4, Article 27. Publication date: October 2021. 